\title{
Esophageal Lipoma and Liposarcoma: A Systematic Review
}

\author{
Davide Ferrari $^{1,2}$ (1) $\cdot$ Daniele Bernardi $^{2} \cdot$ Stefano Siboni $^{2} \cdot$ Veronica Lazzari $^{2} \cdot$ Emanuele Asti $^{2}$. \\ Luigi Bonavina ${ }^{1,2}$
}

\begin{abstract}
Background Esophageal lipomatous tumors, also reported as fibrovascular polyp, fibrolipoma, angiolipoma, and liposarcoma, account for less than $1 \%$ of all benign mesenchymal submucosal tumors of the esophagus. Clinical presentation and therapy may differ based on location, size, and morphology. A comprehensive and updated systematic review of the literature is lacking.

Methods A systematic review of the literature was performed according to PRISMA guidelines. Pubmed, Embase, Cochrane, and Medline databases were consulted using MESH keywords. Non-English written articles and abstracts were excluded. Sex, age, symptoms at presentation, diagnosis, tumor location and size, surgical approach and technique of excision, pathology, and morphology were extracted and recorded in an electronic database.

Results Sixty-seven studies for a total of 239 patients with esophageal lipoma or liposarcoma were included in the qualitative analysis. Among 176 patients with benign lipoma, the median age was 55. The main symptoms were dysphagia (64.2\%), transoral polyp regurgitation (32.4\%), and globus sensation (22.7\%). The majority of lipomas $(85.7 \%)$ were intraluminal polyps, with a stalk originating from the upper esophagus. Overall, 165 patients underwent excision of the mass through open surgery (65.5\%), endoscopy (27.9\%), or laparoscopy/thoracoscopy (3.6\%). Only 5 (3\%) of patients required esophagectomy. Of the 11 untreated patients with an intraluminal polyp, 7 died from asphyxia. Overall, liposarcoma was diagnosed in 63 patients, and 12 (19\%) underwent esophagectomy.

Conclusion Esophageal lipomatous tumors are rare but potentially lethal when are intraluminal and originate from the cervical esophagus. Modern radiological imaging has improved diagnostic accuracy. Minimally invasive transoral and laparoscopic/thoracoscopic techniques represent the therapeutic approach of choice.
\end{abstract}

Luigi Bonavina

luigi.bonavina@unimi.it

Davide Ferrari

ferraridav93@gmail.com

Daniele Bernardi

daniele.bernardi@grupposandonato.it

Stefano Siboni

stesibo@gmail.com

Veronica Lazzari

veronica.lazzari@grupposandonato.com
Emanuele Asti

emanuele.asti@unimi.it

1 Department of Biomedical Sciences for Health, Division of General and Foregut Surgery, University of Milan, IRCCS Policlinico San Donato, 20133 Milan, Italy

2 Division of General and Foregut Surgery, IRCCS Policlinico San Donato, Piazza Edmondo Malan, San Donato Milanese, 20097 Milan, Italy 


\section{Introduction}

Esophageal lipomatous tumors are uncommonly diagnosed and account for less than $1 \%$ of all benign esophageal neoplasms [1-3]. They can present as an intramural submucosal mass, or as an intraluminal mass with a long and narrow pedicle covered by intact mucosa and tethered to the cervical esophagus. The pedicle is usually vascularized, can be quite mobile in the esophageal lumen, and may reach into the stomach [4-6]. It is speculated that lipomas originating from the cervical esophagus near the cricopharyngeus tend to elongate and to assume a polypoid shape due to looseness of the submucosa and the longlasting traction effect of esophageal peristalsis [3, 5, 7]. Despite esophageal lipomas are also described and reported as fibrovascular polyp, fibrolipoma, or angiolipoma [7], these neoplasms consistently share the presence of variable amounts of mature adipocytes and fibrovascular septa [4]. Due to their indolent growth pattern [8], most esophageal lipomas are estimated to be clinically silent and are incidentally found on radiographic imaging [2, 3]. In contrast, lipomas over $4 \mathrm{~cm}$ in size present with dysphagia, regurgitation, and/or respiratory symptoms [9]. Recurrent and life-threatening asphyxia due to oral prolapse of a mobile intraluminal lipoma is a bizarre clinical manifestation that can lead to sudden death from asphyxia [5, 6, 10]. The diagnosis is essentially based on upper gastrointestinal endoscopy, barium esophagogram, and computed tomography [11]. Excision of esophageal lipomatous tumors can be performed extraluminally, through an esophagotomy, or

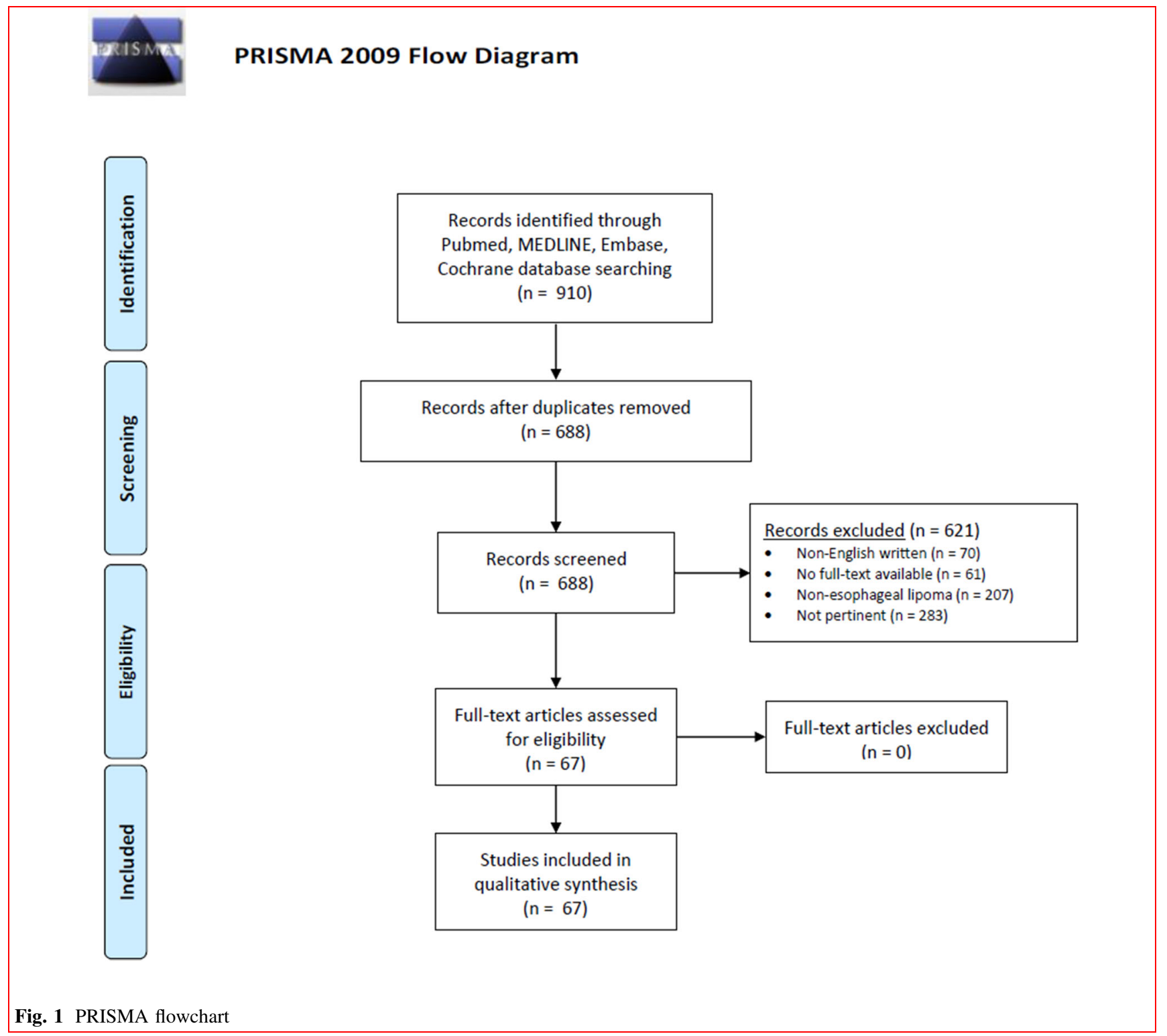


endoluminally through an endoscopic approach [11-13]. Liposarcoma is extremely rare, although some neoplasms presenting as giant fibrovascular polyps have been diagnosed as liposarcomas on histopathological assessment [14].

The aim of this study was to provide a comprehensive and updated systematic literature review on the clinicalpathological features and therapeutic approach to esophageal lipomatous tumors.

\section{Material and methods}

An extensive literature search was conducted according to the Preferred Reporting Items for Systematic Reviews and Meta-analyses (PRISMA) statement [15]. Two independent authors (DF, DB) conducted the literature search to identify all English-written reports on esophageal lipoma and liposarcoma. Pubmed, Embase, Cohcrane, and Medline databases were accessed to May 1, 2020, using Google Chrome browser (Google, California, USA). The following specific MeSH keywords were used: esophagus; lipoma; polyp; fibrolipoma; angiolipoma; liposarcoma. The references list of each selected article was consulted to broaden the search. Articles where included in the research database if they reported a case of lipoma, fibrovascular polyp, fibrolipoma, angiolipoma, or liposarcoma of the esophagus in the adult or pediatric population. Tumors proximal to the cricopharyngeus were excluded. Non-English written articles and abstracts were excluded from final analysis (Fig. 1). Three authors (DF, DB, VL) independently extracted data from the appropriate studies, including author name, year, journal of publication, number of patients, age, sex, symptoms, diagnosis, location,

Table 1 Demographics and clinical characteristics of patients with esophageal lipoma

\begin{tabular}{ll}
\hline & $N=176$ \\
\hline Median age, years (IQR) & $55(20)$ \\
Male, $n(\%)$ & $117(66.5)$ \\
Location of the tumor & \\
Cervical esophagus, $n(\%)$ & $150(85.7)$ \\
Thoracic esophagus, $n(\%)$ & $11(6.3)$ \\
Distal esophagus, $n(\%)$ & $14(8)$ \\
Site of the tumor & \\
Intraluminal, $n(\%)$ & $156(88.6)$ \\
Intramural, $n(\%)$ & $20(11.4)$ \\
Duration of symptoms, months $( \pm \mathrm{SD})$ & $12.2( \pm 10.2)$ \\
Adverse events, $n(\%)$ & $18(10.2)$ \\
Deaths, $n(\%)$ & $8(4.5)$ \\
\hline
\end{tabular}

morphology, size, therapeutic approach, histological findings, and adverse events. The methodological quality of the studies was assessed based on the most critical factors that increase the risk of bias in this specific context [16].

Inter-rater reliability was assessed for study selection and extraction of data using Cohen's kappa coefficient. In case of disagreements between the authors, discussion and agreement were required; if consensus was not reached, a senior author (LB) made the decision.

Continuous data are reported as median \pm interquartile range (IQR) or mean \pm standard deviation (SD). Categorical demographic and baseline variables are reported as proportions or frequencies. Statistical analysis included Chi-square test to compare percentages and Mann-Whitney $\mathrm{U}$ test to compare continuous data. A $p$ value $<0.05$ was considered statistically significant. Statistical analyses were performed using SPSS software 23.0 (IBM, Armonk, New York, USA).

\section{Results}

Sixty-five case reports, $[1,2,5,6,8,10,12,13,17-73]$ and two reviews [11, 74], published between 1955 and May 2020 , were included in the systematic review. The total number of patients was 239 , including 176 with lipoma and 63 with liposarcoma. All studies had a retrospective design, and a low $(n=59)$ to moderate risk $(n=8)$ for bias based on a global assessment of methodological quality [16].

\section{Esophageal lipoma}

The median patient age was 55 (IQR 20), and the male to female ratio $2: 1$. The majority of tumors were intraluminal

Table 2 Presenting symptoms in 176 patients with esophageal lipoma

\begin{tabular}{ll}
\hline Symptom & $n(\%)$ \\
\hline Dysphagia & $113(64.2)$ \\
Tumor regurgitation & $57(32.4)$ \\
Lump sensation & $40(22.7)$ \\
Weight loss & $32(18.2)$ \\
Respiratory symptoms & $28(15.9)$ \\
Cough & $16(9)$ \\
Asphyxia & $12(6.8)$ \\
Food regurgitation & $27(15.3)$ \\
Anemia & $17(9.7)$ \\
Chest Pain & $14(8)$ \\
Odynophagia & $13(7.4)$ \\
Heartburn & $8(4.6)$ \\
\hline
\end{tabular}


Table 3 Therapeutic approach to esophageal lipoma in 165 patients

\begin{tabular}{llll}
\hline Therapy & $n(\%)$ & Morbidity & Mortality \\
\hline Cervicotomy & $63(38.2)$ & 1 (anastomotic leak) & 0 \\
Endoscopy & $46(27.9)$ & 1 (mucosal laceration) & 1 (postoperative bleeding) \\
Flexible & $39(23.7)$ & & \\
Rigid & $7(4.2)$ & 1 (pneumothorax) & 0 \\
Thoracotomy & $44(26.7)$ & 2 (anastomotic leak, pneumothorax) & 0 \\
Esophagectomy & $5(3)$ & 0 & 0 \\
Laparoscopy & $3(1.8)$ & 0 & 0 \\
Thoracoscopy & $3(1.8)$ & 0 & 0 \\
Laparotomy & $1(0.6)$ & &
\end{tabular}

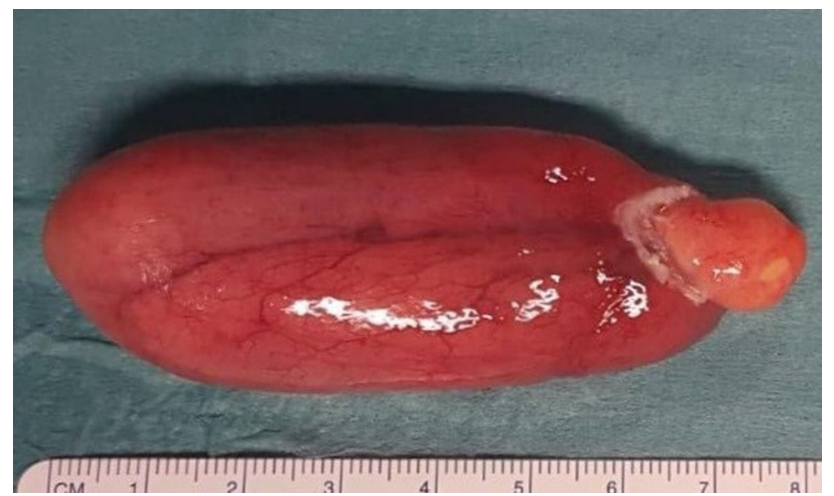

Fig. 2 Intraluminal polyp excised with endoscopic snare technique

$(n=156,88.6 \%)$, and were generally described as fibrovascular polyps (Table 1). The most frequent site of origin was the cervical esophagus $(85.7 \%)$, followed by the distal (8\%) and the mid-thoracic esophagus (6.3\%). In 43 of the 65 papers, the time to first physician consultation averaged $12.2( \pm 10.2)$ months from the onset of symptoms. The most frequent symptom at presentation was dysphagia $(n=113)$, followed by polyp regurgitation $(n=57)$, and globus sensation $(n=40)$. Weight loss was reported in 32 patients, and averaged $8 \mathrm{~kg}$. Respiratory symptoms were reported by $15.9 \%$ of patients and ranged from mild cough to aspiration pneumonia. Asphyxia secondary to polyp regurgitation occurred in 12 patients $(6.8 \%)$. The reporting of polyp regurgitation was often impressive ("fleshy tissue extruded from the mouth") and accompanied by spectacular pictures showing the mass in the throat or prolapsing from the mouth. Most patients admitted to re-swallow the polyp, and occasionally to capture it to convince a skeptical physician. Anemia was reported in 17 patients $(9.6 \%)$ and was attributed to occult bleeding originating from the ulcerated tip of a long fibrovascular polyp $(>15 \mathrm{~cm})$ reaching the

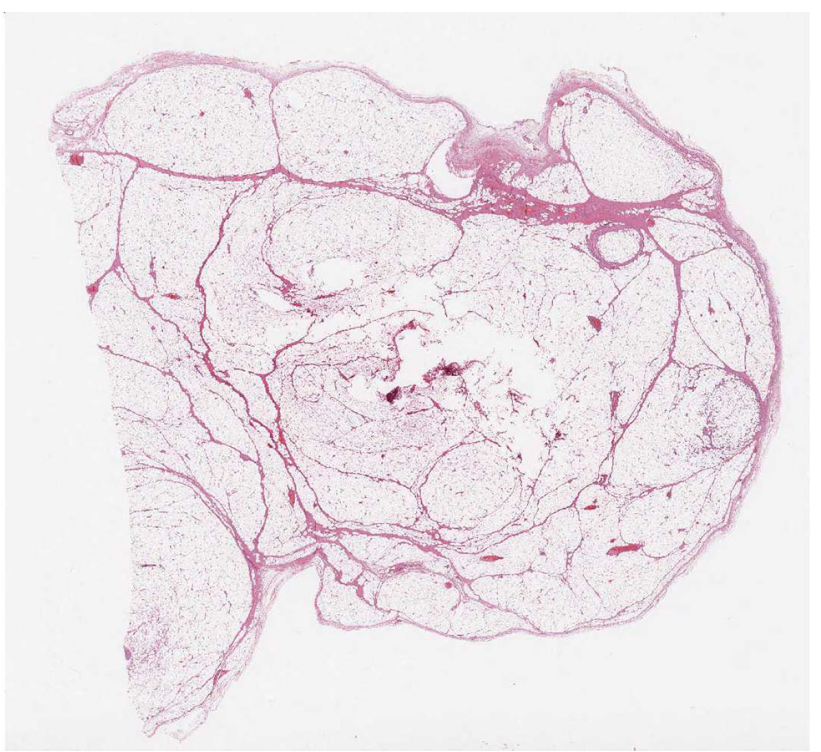

Fig. 3 Microscopic transverse section revealing benign esophageal lipoma

gastroesophageal junction and exposed to gastroesophageal reflux [12, 24, 35, 43, 58]. Physical examination was unremarkable in most patients, except those presenting with acute transoral polyp regurgitation $(n=3)$ (Table 2).

Further diagnostic evaluation included upper gastrointestinal endoscopy, barium swallow (mainly in studies published before the $1980^{\prime}$ ), or chest and neck computed tomography (CT). Endoscopy failed to detect a fibrovascular polyp in up to $33 \%$ of cases [11]. Barium swallow study usually showed a luminal narrowing at the level of the tumor. CT scan, performed in 56 patients, was consistently diagnostic and showed an hypoattenuating submucosal mass with fat density (Hounsfield units between -90 and -110) [2, 59]. Magnetic resonance was performed in 11 patients and showed a mass with hyperintense signal on T1 and T2-weighted images. Endoscopic 
Fig. 4 Prevalence of polyp entrapment in the throat and mortality related to asphyxia in patients treated or not treated for esophageal lipoma

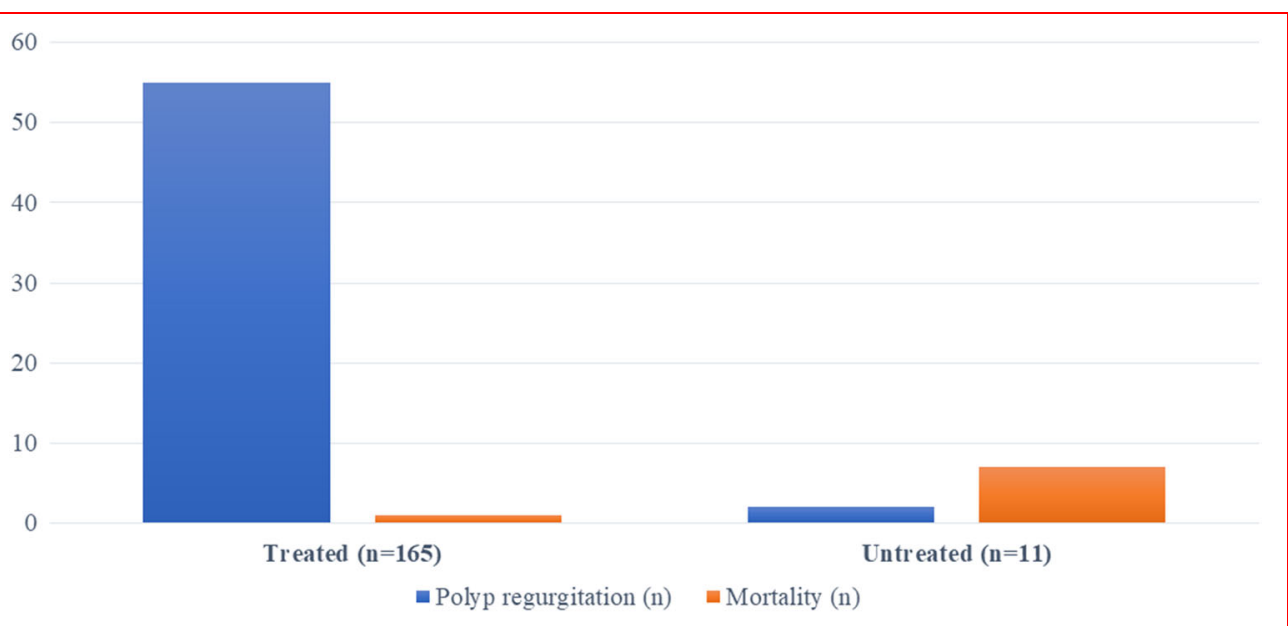

Table 4 Comparison between intramural and intraluminal lipomas of the esophagus

\begin{tabular}{|c|c|c|c|}
\hline & Intramural $(n=20)$ & Intraluminal $(n=156)$ & $p$ \\
\hline Male, $n(\%)$ & $14(70)$ & $103(66)$ & 0.71 \\
\hline Age, years, mean $( \pm S D)$ & $54.7( \pm 20.8)$ & $55.6( \pm 15.9)$ & 0.82 \\
\hline \multicolumn{4}{|l|}{ Site $(\%)$} \\
\hline Cervical & $9(47.4)$ & $141(90.4)$ & \\
\hline Thoracic & $4(21.1)$ & $7(4.5)$ & $<0.01$ \\
\hline Distal & $6(31.5)$ & $8(5.1)$ & \\
\hline \multicolumn{4}{|l|}{ Size $( \pm \mathrm{SD})$} \\
\hline Length & $9.46( \pm 5.5)$ & $12.5( \pm 5.3)$ & 0.02 \\
\hline Width & $4.3( \pm 2.1)$ & $3.8( \pm 2.1)$ & 0.32 \\
\hline Duration of symptoms, months ( \pm SD) & $11.6( \pm 8.1)$ & $11.1( \pm 9.3)$ & 0.82 \\
\hline Adverse events, $n(\%)$ & $2(10)$ & $16(10.2)$ & 0.97 \\
\hline Deaths, $n(\%)$ & $0(0)$ & $8(5.2)$ & 0.30 \\
\hline Hospital stay, days, mean ( \pm SD) & $9.2( \pm 8.3)$ & $7.6( \pm 6.7)$ & 0.33 \\
\hline
\end{tabular}

ultrasound, performed in 13 patients, was considered especially useful to assess the presence of feeding vessels in the stalk of a fibrovascular polyp [36]. Positron emission tomography was performed in 2 patients to exclude malignancy $[57,66]$. In one patient with intramural lipoma of the distal esophagus, high-resolution esophageal manometry revealed esophageal pan-pressurization, but the lower esophageal sphincter was properly relaxing upon swallowing [70].

The therapeutic approach varied depending on symptoms at presentation, location of the mass, and time of publication of the article. The most common excisional approach was through a left cervical esophagotomy ( $n=63)$, followed by endoscopic resection $(n=46)$ via flexible endoscopy in 39 patients and rigid endoscopy in 7 , and by open esophagotomy through a right thoracotomy $(n=44)$. Only $3 \%$ of the patients underwent a minimally invasive approach by thoracoscopy ( $n=3$, including one robotic-assisted enucleation) or laparoscopy $(n=3)$. Only 5 patients $(3 \%)$ underwent esophagectomy. Of note, five (3\%) of the 165 patients were operated emergently due to asphyxia secondary to polyp regurgitation, and required tracheotomy and subsequent cervical esophagotomy $(n=2)$, primary cervical esophagotomy and mass excision $(n=2)$, and endoscopic resection $(n=1)$.

Overall, $6(3.6 \%)$ postoperative complications were reported including esophageal anastomotic leak, pneumothorax, and esophageal mucosa laceration after endoscopic resection treated with a temporary fully covered stent. One patient $(0.6 \%)$ died of hemorrhage following incomplete endoscopic removal. The patients were discharged at an average of $7.8 \pm 7.2$ (range 0-32 days) after intervention, as reported in 36 papers. No deaths occurred 
Table 5 Demographic, clinical, and pathological characteristics of patients with esophageal liposarcoma

\begin{tabular}{ll}
\hline & $N=63$ \\
\hline Median age, years (IQR) & $66(21)$ \\
Male, $n(\%)$ & $46(73)$ \\
Location of the tumor & \\
Cervical esophagus, $n(\%)$ & $46(73)$ \\
Thoracic esophagus, $n(\%)$ & $8(12.7)$ \\
Distal esophagus, $n(\%)$ & $5(7.9)$ \\
Not reported & $4(6.4)$ \\
Site of the tumor & \\
Intraluminal, $n(\%)$ & $54(85.7)$ \\
Intramural, $n(\%)$ & $9(14.3)$ \\
Histology & $40(63.5)$ \\
Well-differentiated, $n(\%)$ & $7(11.1)$ \\
Myxoid, $n(\%)$ & $1(1.6)$ \\
Pleomorphic, $n(\%)$ & $9(14.3)$ \\
Dedifferentiated, $n(\%)$ & $6(9.5)$ \\
Not specified & \\
Local recurrence & $6(9.5)$ \\
Death related to disease recurrence & $2(3.2)$ \\
\hline
\end{tabular}

among the 113 cases described after the $1980^{\prime}(p<0.01)$ (Table 3).

All tumors were described as lipomatous benign masses with variable amount of mature adipose tissue and fibrovascular septa (Figs. 2, 3); the final pathologic diagnosis was fibrovascular polyp in $42.3 \%$, lipoma in $33.4 \%$, fibroma in $14.7 \%$, fibrolipoma in $8.3 \%$ of patients, and angiolipoma in $1.3 \%$.

Of the 11 patients who were not treated surgically or endoscopically, 7 died of acute asphyxia due to entrapment of the polyp in the throat and/or aspiration. The remaining 4 patients refused treatment; 2 of them were followed-up up to three years with CT scan which showed no increase in size of the mass (Fig. 4).

Table 4 shows a comparative analysis of intraluminal and intramural tumors. Intraluminal lipomas were significantly longer $(p=0.02)$ and arised more frequently from the cervical esophagus $(p<0.01)$, while intramural lipomas were mostly located in the distal esophagus $(p<0.01)$. Overall, adverse events and deaths occurred more commonly in patients with intraluminal polyps $(p=0.97)$.

\section{Esophageal liposarcoma}

Sixty-three patients with esophageal liposarcoma were found, 62 from a review [74] and one more recent case report [73]. Most liposarcomas were polypoid; in 10 patients, an endoscopic approach was used, whereas 9 patients were treated through a left cervical incision. Esophagectomy was performed in 12 patients. The main patients' features are reported in Table 5.

\section{Discussion}

The present systematic review shows that the vast majority of esophageal lipoma is represented by fibrovascular polyps originating from the cervical esophagus. All adverse events related to the natural history of esophageal lipoma or to the consequences of therapeutic intervention occurred before the $1980^{\prime}$, reflecting in part limited use of radiological imaging that may have accounted for late diagnosis. In fact, five patients required emergent tracheotomy or intubation, and 7 of 11 untreated patients died of asphyxia, thus underscoring the importance of early diagnosis and endoscopic treatment [27].

After the 1980s, there has been a shift toward first-line endoscopic excision of fibrovascular polyps, and this procedure has largely replaced open cervical esophagotomy. Since the review of Caceres et al. [11], the rate of cervical lipoma approached through endoscopy has grown from 21.5 to $46 \%(p<0.01)$.

Today, thanks to technological advancements, flexible endoscopy is the first-line approach even in patients with giant fibrovascular polyps. The risk of bleeding from the area of mucosal transection and from the central vascular axis of the polyp is minimal if the stalk is visible and a snare device can be easily applied. In some circumstances, a cross-over approach with rigid endoscopy could be crucial to avoid open surgery. A recent meta-analysis comparing flexible and rigid endoscopy showed that both approaches were safe and effective for retrieval of upper esophageal foreign bodies [75]. The Weerda diverticuloscope, commonly used for the treatment of Zenker diverticulum, allows to introduce a rigid 5-mm telescope along with multiple devices, such as graspers, forceps or endostaplers [30].

When the snare technique is not feasible because of the difficulty of trapping the polyp stalk or the risk of an incomplete resection, endoscopic submucosal dissection (ESD) is another option that has been shown to be safe even in patients with giant fibrovascular polyps [5, 53, 63]. Compared to the snare technique, ESD can increase the chance of a radical excision of the polyp with clear margins. In the present systematic review, there were 5 reported recurrences or malignant transformations after initial snare excision of an apparently benign lipoma. Unfortunately, the resection margin was not evaluated $[11,12]$. Two studies reviewing the clinical-pathological and molecular features of esophageal lipoma and 


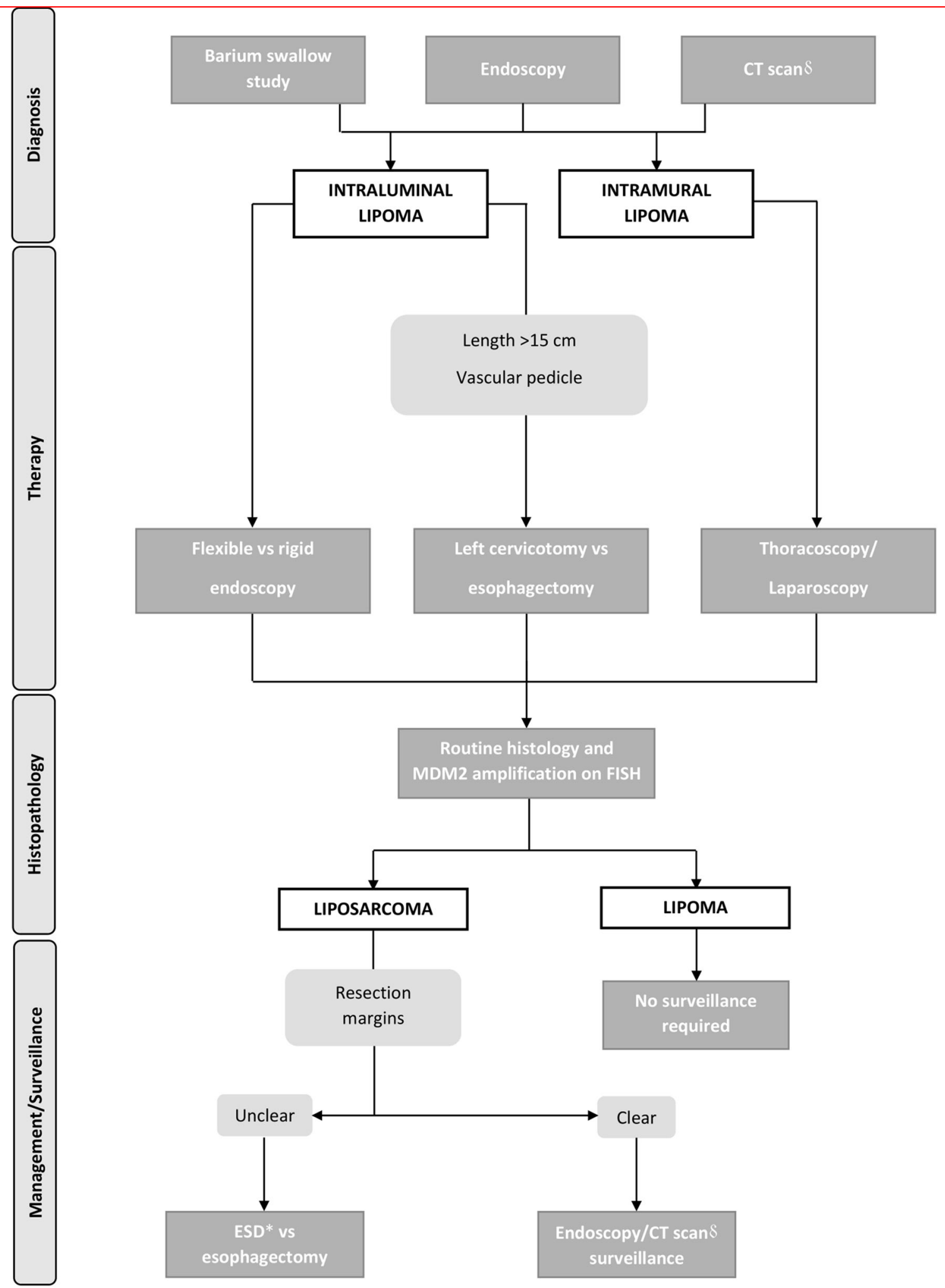

Fig. 5 Proposed algorithm for diagnosis, treatment, histopathological assessment, and surveillance of esophageal lipomatous tumors. * $\mathrm{ESD}=$ Endoscopic Submucosal Dissection; $\delta \mathrm{CT}$ scan = computed tomography scan 
liposarcoma found MDM2 amplification by fluorescence in situ hybridization in all cases, with some of these patients presenting recurrent disease $[14,76]$. Therefore, a careful histopathological assessment of the resection margin, is recommended after resection of an apparently benign lipoma, and patients should be advised about the need for endoscopic/radiologic surveillance. Given the potential malignancy of esophageal lipomatous neoplasms, we suggest an algorithm for diagnosis, treatment, and surveillance (Fig. 5).

The rarity of esophageal lipoma, the heterogeneity of reported data, the differences in histopathological assessment and classification, and the therapeutic selection bias are the main study limitations.

In conclusion, esophageal lipoma is an uncommon but potentially life-threatening condition. Clinical presentation and treatment remain heterogeneous in the literature. For polyps of the upper esophagus, early intraluminal approach by flexible or rigid endoscopy and careful histopathological assessment is recommended. Distal esophageal and intramural lesions may safely and effectively be approached by laparoscopy or thoracoscopy to reduce patient hospitalization and potential morbidity related to open surgery.

Acknowledgements This work was supported by AIRES (Associazione Italiana Ricerca ESofago).

Author contributions DF, DB, EA, SS, and LB designed the study. $\mathrm{DF}, \mathrm{DB}$, and VL collected the data. DF, SS, and LB wrote the manuscript. All authors reviewed the final version of the manuscript.

Funding Open access funding provided by Università degli Studi di Milano within the CRUI-CARE Agreement.

\section{Compliance with ethical standard}

Conflict of interest The authors declared that there is no conflict of interest.

Open Access This article is licensed under a Creative Commons Attribution 4.0 International License, which permits use, sharing, adaptation, distribution and reproduction in any medium or format, as long as you give appropriate credit to the original author(s) and the source, provide a link to the Creative Commons licence, and indicate if changes were made. The images or other third party material in this article are included in the article's Creative Commons licence, unless indicated otherwise in a credit line to the material. If material is not included in the article's Creative Commons licence and your intended use is not permitted by statutory regulation or exceeds the permitted use, you will need to obtain permission directly from the copyright holder. To view a copy of this licence, visit http://creativecommons. org/licenses/by/4.0/.

\section{References}

1. Yekeler E, Yazicioglu A, Subasi M et al (2016) Giant Esophageal lipoma as an uncommon cause of diverticula. Case Rep Gastroenterol 10:446-451. https://doi.org/10.1159/000447487

2. Feldman J, Tejerina M, Hallowell M (2012) Esophageal lipom a: a rare tumor. J Radiol Case Rep 6:17-22. https://doi.org/10.3941/ jrer.v6i7.1015

3. Taylor AJ, Stewart ET, Dodds WJ (1990) Gastrointestinal lipomas: a radiologic and pathologic review. Am J Roentgenol 155:1205-1210. https://doi.org/10.2214/ajr.155.6.2122666

4. Lewis RB, Mehrotra AK, Rodriguez P et al (2013) From the radiologic pathology archives: esophageal neoplasms: radiologicpathologic correlation. RadioGraphics 33:1083-1108. https://doi. org/10.1148/rg.334135027

5. Yamazaki K, Yoshida Y, Maruta A et al (2019) Endoscopic resection of a giant fibrovascular esophageal polyp by use of a scissor-type knife. VideoGIE 4:451-453. https://doi.org/10.1016/ j.vgie.2019.06.004

6. Endara SA, Davalos GA, Yepez RJ et al (2019) Asphyxia caused by a giant fibrovascular polyp of the esophagus. ACG Case Reports J 6:e0126. https://doi.org/10.14309/crj. 0000000000000126

7. Levy AD (2013) Esophagus: benign neoplasms. In: Abdominal imaging. Springer Berlin Heidelberg, pp 149-158

8. Samad L, Ali M, Ramzi H, Akbani Y (1999) Respiratory distress in a child caused by lipoma of the esophagus. J Pediatr Surg 34:1537-1538. https://doi.org/10.1016/S0022-3468(99)90122-7

9. Hurwitz M, Redleaf P, Williams H et al (1967) Lipomas of the gastrointestinal tract. An analysis of seventy-two tumors. Am J Roentgenol Radium Ther Nucl Med 99:84-89

10. Ongkasuwan J, Anzalone CL, Salazar E et al (2017) Presentation and management of giant fibrovascular polyps of the hypopharynx and esophagus. Ann Otol Rhinol Laryngol 126:29-35. https://doi.org/10.1177/0003489416672872

11. Caceres M, Steeb G, Wilks SM et al (2006) Large pedunculated polyps originating in the esophagus and hypopharynx. Ann Thorac Surg 81:393-396

12. Lee SY, Chan WH, Sivanandan R et al (2009) Recurrent giant fibrovascular polyp of the esophagus. World J Gastroenterol 15:3697-3700. https://doi.org/10.3748/wjg.15.3697

13. Kanaan S, DeMeester TR (2007) Fibrovascular polyp of the esophagus requiring esophagectomy. Dis Esophagus 20:453-454. https://doi.org/10.1111/j.1442-2050.2007.00710.x

14. Graham RP, Yasir S, Fritchie KJ et al (2018) Polypoid fibroadipose tumors of the esophagus: "Giant fibrovascular polyp" or liposarcoma? a clinicopathological and molecular cytogenetic study of 13 cases. Mod Pathol 31:337-342. https://doi.org/10. 1038/modpathol.2017.140

15. Moher D, Liberati A, Tetzlaff J et al (2009) Preferred reporting items for systematic reviews and meta-analyses: the PRISMA Statement. PLoS Med 6:e1000097. https://doi.org/10.1371/jour nal.pmed.1000097

16. Murad MH, Sultan S, Haffar S et al (2018) Methodological quality and synthesis of case series and case reports. Evid Based Med 23:60-63. https://doi.org/10.1136/bmjebm-2017-110853

17. Nora PF (1964) Lipoma of the esophagus. Am J Surg 108:353-356. https://doi.org/10.1016/0002-9610(64)90351-4

18. Tolis GA, Shields TW (1967) Intramural lipoma of the esophagus. Ann Thorac Surg 3:60-62. https://doi.org/10.1016/S00034975(10)66689-1

19. Ovnat A, Peiser J, Solomon H et al (1985) Obstructing lipomas of the esophagus and ileocecal valve. J Clin Gastroenterol 7:279-280. https://doi.org/10.1097/00004836-198506000-00020 
20. Akiyama S, Kataoka M, Horisawa M et al (1990) Lipoma of the esophagus-report of a case and review of the literature. Jpn J Surg 20:458-462. https://doi.org/10.1007/BF02470832

21. Hasan N, Mandhan P (1994) Respiratory obstruction caused by lipoma of the esophagus. J Pediatr Surg 29:1565-1566. https:// doi.org/10.1016/0022-3468(94)90217-8

22. Sossai P, De Bernardin M, Bissoli E et al (1996) Lipomas of the esophagus: a new case. Digestion 57:210-212. https://doi.org/10. $1159 / 000201342$

23. Wang CY, Hsu HS, Wu YC et al (2005) Intramural lipoma of the esophagus. J Chin Med Assoc 68:240-243. https://doi.org/10. 1016/S1726-4901(09)70216-3

24. Weigel TL, Schwartz DC, Gould JC et al (2005) Transgastric laparoscopic resection of a giant esophageal lipoma. Surg Laparosc Endosc Percutan Tech 15:160-162. https://doi.org/10. 1097/01.sle.0000166966.49274.83

25. Algin C, Haciaglu A, Aydin T, et al (2006) Esophagectomy in esophageal lipoma: report of a case.-PubMed-NCBI. In: Turkish J. Gastroenterol. https://www.ncbi.nlm.nih.gov/pubmed/ 16830292. Accessed 6 May 2020

26. Jensen EH, Klapman JB, Kelley ST (2006) Angiolipoma of the esophagus: a rare clinical dilemma. Dis Esophagus 19:203-207

27. Luthen R, Janzik U, Derichs R et al (2006) Giant fibrovascular polyp of the esophagus. Eur J Gastroenterol Hepatol 18:1005-1009. https://doi.org/10.1097/01.meg.0000228971. 34280.57

28. Maruyama K, Motoyama S, Okuyama M et al (2007) Cervical approach for resection of a pedunculated giant atypical lipomatous tumor of the esophagus. Surg Today 37:173-175. https://doi. org/10.1007/s00595-006-3357-8

29. Liu C-H, Chang H-C, Goan Y-G (2008) Large pedunculated lipoma of the esophagus. J Formos Med Assoc 107:424-427. https://doi.org/10.1016/S0929-6646(08)60109-6

30. Pham AM, Rees CJ, Belafsky PC (2008) Endoscopic removal of a giant fibrovascular polyp of the esophagus. Rhinol Laryngol 117:587-590

31. Goto A, Suzuki M, Iizuka K et al (2010) Regurgitation of a mass into the mouth: a fibrovascular polyp of the esophagus. Endoscopy. https://doi.org/10.1055/s-0030-1255618

32. Peltz M, Estrera AS (2010) Resection of a giant esophageal fibrovascular polyp. Ann Thorac Surg 90:1017-1019. https://doi. org/10.1016/j.athoracsur.2010.02.049

33. Cuttitta A, Annese V, Tancredi A et al (2011) Giant esophageal lipoma. Updates Surg 63:125-127

34. Janarthanan K, Shetty S, Mohanakrishnan A et al (2011) Esophageal lipoma presenting as a long tongue!! Indian J Gastroenterol 30:187. https://doi.org/10.1007/s12664-011-0117-5

35. Goenka AH, Sharma S, Ramachandran V et al (2011) Giant fibrovascular polyp of the esophagus: report of a case. Surg Today 41:120-124. https://doi.org/10.1007/s00595-009-4212-5

36. Vagli P, Solito B, Neri E et al (2012) Giant fibrovascular polyp of the esophagus-imaging techniques for proper treatment planning: report of two cases. Abdom Imaging 37:512-518. https://doi.org/ 10.1007/s00261-011-9787-9

37. Kau RL, Patel AB, Hinni ML (2012) Giant fibrolipoma of the esophagus. Case Rep Otolaryngol 2012:1-3. https://doi.org/10. $1155 / 2012 / 406167$

38. Trakál JJ, Sarquis GJ, Muñoz JA et al (2012) Giant fibrovascular polyp of the esophagus: a novel technical approach. Case Rep Gastrointest Med 2012:1-3. https://doi.org/10.1155/2012/562363

39. Yapali S, Oruc N, Harman M et al (2013) Giant esophageal lipoma presenting with gastroesophageal reflux symptoms. J Gastrointestin Liver Dis 22(1):8-8

40. Madeira FP, Justo JWR, Wietzycoski CR et al (2013) Giant fibrovascular polyp of the esophagus: a diagnostic challenge.
ABCD Arq Bras Cir Dig (São Paulo) 26:71-73. https://doi.org/ 10.1590/S0102-67202013000100017

41. Tsalis K, Antoniou N, Kalfadis S et al (2013) Laparoscopic enucleation of a giant submucosal esophageal lipoma. Case report and literature review. Am J Case Rep 14:179-183. https://doi.org/ 10.12659/AJCR.883928

42. Murino A, Eisendrath P, Blero D et al (2014) A giant fibrovascular esophageal polyp endoscopically resected using 2 gastroscopes simultaneously (with videos). Gastrointest Endosc 79:834-835. https://doi.org/10.1016/j.gie.2014.01.001

43. Ćuk V, Knežević-Ušaj S, Ignjatović M et al (2014) Giant esophageal fibrovascular polyp with clinical behaviour of inflammatory pseudotumor: A case report and the literature review. Vojnosanit Pregl 71:784-791. https://doi.org/10.2298/ VSP130219058C

44. Di Mitri R, Mocciaro F, Lipani M et al (2014) One-step endoscopic removal of a giant double esophageal fibrovascular polyp. Dig Liver Dis 46:660-662. https://doi.org/10.1016/j.dld.2014.02. 008

45. Dhoon TQ, Gerber JL, Tran TB et al (2014) An unusual cause of airway obstruction in a patient in the endoscopy suite. A\&A Case Rep 3:15-19. https://doi.org/10.1213/xaa.0000000000000040

46. Park JS, Bang BW, Shin J et al (2014) A case of esophageal fibrovascular polyp that induced asphyxia during sleep. Clin Endosc 47:101-103. https://doi.org/10.5946/ce.2014.47.1.101

47. Cheriyan D, Guy C, Burbridge R (2015) Giant esophageal lipoma: endoscopic resection. Gastrointest Endosc 82:742. https://doi.org/10.1016/j.gie.2015.05.005

48. Li J, Yu H, Pu R et al (2016) Gastroscopic removal of a giant fibrovascular polyp from the esophagus. Thorac Cancer 7:363-366. https://doi.org/10.1111/1759-7714.12319

49. Qinying W, Wei L, Shuihong Z (2015) Large pedunculated lipoma of the esophagus: report of a case and review of literature. J Cancer Res Ther 11:1031. https://doi.org/10.4103/0973-1482. 154089

50. Zhang H, Nie RH (2015) A rare case of giant fibrovascular polyp of the esophagus. Saudi Med 36:1348-1350. https://doi.org/10. $15537 / \mathrm{smj} .2015 .11 .12531$

51. Zhao X, Wang X, Li A et al (2016) Endoscopic resection of a giant esophageal lipoma: a case report. Dis Esophagus 29:1167-1169. https://doi.org/10.1111/dote.12400

52. Lobo N, Hall A, Weir J et al (2016) Endoscopic resection of a giant fibrovascular polyp of the oesophagus with the assistance of ultrasonic shears. BMJ Case Rep. https://doi.org/10.1136/bcr2015-214158

53. Baldaque-Silva F, Marques M, Sanchez-Hernandez E et al (2016) Endoscopic submucosal dissection of a giant esophageal lipoma. Am J Gastroenterol 111:1680

54. Lorenzo D, Gonzalez JM, Barthet M (2016) Endoscopic resection of a giant esophageal fibrovascular polyp. Endoscopy 48:E69E70

55. Jo DH, Chon HK, Woo SH et al (2016) Endoscopic resection of a giant esophageal lipoma causing sudden choking. Korean $\mathrm{J}$ Gastroenterol 68:210-213. https://doi.org/10.4166/kjg.2016.68.4. 210

56. Medici JR, Gomez NL, Wright FG et al (2016) Giant esophageal lipoma. J Gastrointest Surg 20:473-475. https://doi.org/10.1007/ s11605-015-3014-x

57. Sestini S, Gisabella M, Pastorino U et al (2016) Presenting symptoms of giant fibrovascular polyp of the oesophagus: case report and literature review. Ann R Coll Surg Engl 98:e71-e73. https://doi.org/10.1308/rcsann.2016.0127

58. Cano J, Hair C, Sealock RJ (2017) Giant esophageal fibrovascular polyp: a rare cause of dysphagia. Clin Gastroenterol Hepatol 15:e93-e94. https://doi.org/10.1016/j.cgh.2016.12.008 
59. How CH, Lee JM (2017) The robotic approach for enucleation of a giant esophageal lipoma. J Robot Surg 11:267-269. https://doi. org/10.1007/s11701-016-0668-7

60. Taira N, Kawasaki H, Koja A et al (2017) Giant pedunclated lipoma of the esophagus: a case report. Int J Surg Case Rep 30:55-57. https://doi.org/10.1016/j.ijscr.2016.11.040

61. Pinto A, Abastado B, Cattan P (2019) An esophageal tumor unlike others: the fibrovascular polyp. J Visc Surg 156:271-273. https://doi.org/10.1016/j.jviscsurg.2018.11.009

62. Ward MA, Beard KW, Teitelbaum EN et al (2018) Endoscopic resection of giant fibrovascular esophageal polyps. Surg Endosc 32:1066-1067. https://doi.org/10.1007/s00464-017-5664-0

63. Rey Ferro M, Pinilla Morales R (2019) Advanced endoscopic resection using endoscopic submucosal dissection technique to resect a giant, lumen-occluding esophageal polyp. Endoscopy 51:E151-E152

64. Mana F, Schoneveld M, Simoens C et al (2019) Transluminal removal of a giant fibrovascular polyp of the esophagus. Acta Gastroenterol Belg 82:437-439

65. François S, Waldbillig C, Lasser L et al (2020) Giant fibrovascular polyp of the esophagus. Gastrointest Endosc 91:442-443. https://doi.org/10.1016/j.gie.2019.09.002

66. Goto W, Sakurai K, Kubo N et al (2020) Successful removal of a giant esophageal lipoma by thoracoscopic enucleation: a case report. Surg Case Rep https://doi.org/10.1186/s40792-020-0782-7

67. Acar N, Acar T, Cengiz F et al (2020) Endoscopic resection for giant oesophageal fibrovascular polyp. Ann R Coll Surg Engl 102:8-9. https://doi.org/10.1308/rcsann.2020.0008

68. Madhusudhan KS, Kumar P, Dash NR (2020) Giant fibrovascular polyp of the esophagus. J Gastrointest Surg. https://doi.org/10. 1007/s11605-020-04606-6
69. Khamaysi I, Asbeh YA (2020) Endoscopic resection of giant esophageal fibrovascular polyp. Turkish J Gastroenterol 31:276-278. https://doi.org/10.5152/tjg.2020.19237

70. Bernardi D, Ferrari D, Siboni S et al (2020) (2020) Minimally invasive approach to esophageal lipoma. J Surg Case Rep 7:1-4. https://doi.org/10.1093/jscr/rjaa123

71. Kinnear JS (1955) Lipoma of the œsophagus report of a case. Br J Surg 42:439-441. https://doi.org/10.1002/bjs.18004217418

72. Schmidt HW, Clagett OT, Harrison EG (1961) Benign tumors and cysts of the esophagus. Ann Otol Rhinol Laryngol 70:1148-1157. https://doi.org/10.1177/000348946107000419

73. Ye YW, Liao MY, Mou ZM, Shi XX, Xie YC (2020) Thoracoscopic resection of a huge esophageal dedifferentiated liposarcoma: a case report. World J Clin Cases 8(9):1698-1704

74. Ng YA, Lee J, Zheng XJ, Nagaputra JC, Tan SH, Wong SA (2019) Giant peduncolated oesophageal liposarcomas a review of literature and resection techniques. Int J Surg Case Rep 64:113-119

75. Ferrari D, Aiolfi A, Riva CG et al (2018) Flexible vs rigid endoscopy in the management of esophageal foreign body impaction: systematic review and meta-analysis. World J Emerg Surg. https://doi.org/10.1186/s13017-018-0203-4

76. Boni A, Lisovsky M, Cin PD et al (2013) Atypical lipomatous tumor mimicking giant fibrovascular polyp of the esophagus: report of a case and a critical review of literature. Hum Pathol 44:1165-1170. https://doi.org/10.1016/j.humpath.2012.10.023

Publisher's Note Springer Nature remains neutral with regard to jurisdictional claims in published maps and institutional affiliations. 